\title{
Labor Productivity: Structural Change and Cyclical Dynamics
}

\author{
Martin Neil Baily*, Eric J. Bartelsman**, and John Haltiwanger*** \\ January 1996 \\ First Draft: January 1995
}

\begin{abstract}
A longstanding puzzle of empirical economics is that average labor productivity declines during recessions and increases during booms. This paper provides a framework to assess the empirical importance of competing hypotheses for explaining the observed procyclicality. For each competing hypothesis we derive the implications for cyclical productivity conditional on expectations of future demand and supply conditions. The novelty of the paper is that we exploit the tremendous heterogeneity in long-run structural changes across individual plants to identify the short-run sources of pro cyclical productivity y. Our findings favor an adj ustment cost model which involves a productivity penalty for downsizing as the largest source of procyclical labor productivity.
\end{abstract}

\footnotetext{
'University of Maryland and NBER; ${ }^{*}$ Federal Reserve Board; ***University of Maryland and NBER; Research Associate and CES Fellow, Census Bureau.

The views expressed herein are solely the authors'. We wish to thank the staff and visiting researchers at the Center for Economic Studies, U.S. Bureau of the Census, for providing a stimulating research environment. We would also like to thank participants of the NBER Summer '93 workshop, the 1995 NBER Small Group Meeting on Alternative Explanations of Employment Fluctuations, the 1995 SITE workshop, the Econometric Society meetings, J anuary 1995, and seminar participants at several universities and institutions for valuable comments and suggestions.
} 
A longstanding puzzle of empirical economics is that average labor productivity declines during recessions and increases during booms. There is no shortage of possible explanations for the procyclicalit $y$ and no shortage of studies attempting to identify the source of the procyclicalit $y .{ }^{1}$ Traditionally, these explanations have fallen into two categories: the underlying theoretical framework was adjusted, by assuming market imperfections or non-standard production technology, or the data were adjusted for assumed measurement error in either output or labor. Despite these possible adjustments, there is no consensus as to which explanation is the predominant cause of the procyclicality. One important reason for this is that most research on this issue uses aggregate or sect oral level data and has difficult y distinguishing underlying causes because they have observationally equivalent implications for these data. ${ }^{2}$ The novelty of this paper is that we exploit the tremendous heterogeneity in long-run structural changes across individual plants to identify the sources of short-run procyclical productivity.

Weanalyze a balanced panel of data on output, employment and hours for all large continuously operating plants in U.S. manufacturing from 1972 through 1988. We use the cross sectional variation in the long-run structural changes of supply and demand conditions to distinguish causes of cyclical movements in plant level productivity. For example, during recessions it is plants that expect desired employment to recover that should hoard labor. Accordingly, if labor hoarding is the prime cause of procyclical productivity, one would expect to find more cyclical variation in productivity for those plants that expected to expand (or at least not contract) their labor force in the long run.

The main points of this paper would have been well known to macroeconomists if appropriate e aggregations or decompositions of the data had been available at an earlier stage. For example, the decomposition of employment changes into gross flow categories-job creation and destruction

-made by Davis and Halt iwanger (1990) has allowed new insights into labor market mechanisms and business cycle determinants. Likewise, we think that a decomposition of data on production and product ive inputs into categories based on the underlying agents' long-run changes (Le., decomposing on the basis oft he long run micro change being positive or negative) provides important information on short-run movements.

Wedistinguish between five possible sources of procyclical labor productivity: labor hoarding, adjust ment costs, external economies, increasing ret urns to scale and compositional changes. The first four are the purview of traditional macroeconomics, while the last is associated with re-

${ }^{1}$ This is a long literature with antecedents in the Dunlop/Tarshis/Keynes debate about the behavior of real wages over the business cycle Notable contributions to this literature across the decades include Kuh (1965), Fair (1969), Solow (1973), Fay and Medoff (1985), Hall (1988) and (1990), Gordon (1990), Bernanke and Parkinson (1991), Burnside, Eichenbaum, and Rebelo (1993).

${ }^{2} \mathrm{~A}$ notable exception is Aizcorbe (1992), who analyses cyclical labor productivity in automobile assembly plants. In auto assemblies labor hoarding turns out to prevalent, likely owing to the specific nature of labor contracts in that industry. 
cent research on the importance of heterogeneity and cross-sectional dynamics for understanding aggregate fluctuations.

One potential problem in using the long-run structural changes to identify the sources of shortrun procyclical productivity is that the latter may influence the former. To correct for possible endogeneit y of long-run changes, we also conduct our analysis using estimates of plant level forecasts, rat her than ex-post realizations, of structural change in demand and supply. This approach is possible because we have time series data starting in 1972, but only consider the cyclical episodes post 1979. Using such forecasts not only addresses the potential endogeneity problems but is consistent with the underlying theory in which the response of an individual producer to an adverse cyclical shock depends on expectations of future demand and cost conditions.

The organization of our paper is as follows: First we give a description of the various hypotheses of sources of procyclical labor productivity and relate these to the existing literature. Next, we describe our sample of plants, and compute the size of the mix shift effects. Following this, we present a model that ties sources of procyclicality to long-run changes, and describe the testable implications for the data. In the empirical section we investigate the cyclical behavior of labor productivity for sub-samples of our data, split according to the long-run changes in plant level employment and product ivity. We also describe our econometric methodology and present our results. We conclude with a summary and ruminations about extensions to this research.

\section{Possible Explanations for Procyclical Productivity}

The first hypothesis is that there are increasing returns to scale at the plant level: Increases in inputs of a given percentage result in increases in output of a larger percentage due to increasing ret urns in plant level production functions. The declines in output that characterize recessions will then naturally lead to declines in total factor productivity, and, depending on the specific parameters of the production function and on the extent of lumpiness in capital use, a decline in labor productivity. If increasing returns is the main explanation for the cyclical productivity puzzle, we also expect to see evidence of increasing returns in the long-rum behavior of plants and in the parameters of the long-run production function.

The second hypothesis is that plants hoard labor over the cycle. We define labor hoarding in a very specific way, one that is linked to the work of Oi (1962). It is argued that firms create firm-specific human capital in their employees. When output levels fall, there are workers that are not needed for current production, but that are retained on the payroll by the firm in order to preserve their human capital.

A key element of this labor hoarding model is that firms must believe that output and labor demand will recover in some future period. It is not worth keeping excess workers on the payroll that will not be used in the future. Under uncertainty, this means that the optimal amount of labor 
hoarding will be smaller the lower is expected future employment.

Closely related to the labor hoarding hypothesis is the mismeasurement hypothesis proposed by Gordon (1990), Saint-Paul (1993) or Bean (1990), Gordon argues that workers are assigned to maintenance or other tasks during periods of low production. It is natural to suggest that workers held for human capital reasons would be assigned to maintenance tasks. The true output of the firm is higher than the measured output in recessions, because the value oft he maintenance tasks is missed. Bean takes this a step further, and argues that during recessions workers build up their human capital by supplying labor to an unmeasured human capital production function. The increased skills learned during the recession can then be employed during the recovery to give an extra productivity impulse. The mismeasurement hypothesis carries the same implications as the labor hoarding hypothesis. The opt imal number of workers assigned to maintenance or human capital accumulation will be smaller the lower is expected future employment.

The third hypothesis is that there is a contemporaneous productivity penalty induced by changing the scale of operations. For example, when output declines, it is difficult to rearrange the production process so as to maintain productivity. Over time, if the lower level of output is sustained, productivity can recover (and perhaps ultimately increase) as the production process is adjusted. ${ }^{3}$

Consider plants that face such a productivity penalty from adjusting the scale of operations. ${ }^{4}$ For plants that are also on a long-run path of employment decline, a temporary downward shock will accelerate the ongoing downsizing which in turn will exacerbate the adjustment cost penalty to productivity. A sufficiently large productivity penalty from downsizing can account for procyclical productivity for such plants. In contrast, plants that expect employment to increase in the longrun will reduce employment less in response to the same temporary downward shock. Thus, in the case of an adjustment-cost-induced productivity penalty, procyclical productivity should be most evident among long-run downsizing plants. This is in cent rast to the labor hoarding case.

The fourth hypothesis is that there are externalities. Productivity is higher when all plants increase output together and productivity falls when the output of most plants falls. An implication

\footnotetext{
${ }^{3}$ The adjustment costs that we emphasize are those that generate productivity penalties associated with changes in the scale of operations. In the terminology of the adjustment cost literature (see, e.g., Brechling (1975)), our specification is one of internal adjustment costs. This contrasts with the predominant recent treatment of employment adjustment costs in the literature (see, e.g., Sargent (1978) and Hamermesh and Pfann (1994)) that formally characterize the adjustment costs as external adjustment costs. In our view, it is somewhat puzzling that the assumption of external adjustment costs has become the standard in the literature. A common motivation for employment adjustment costs is the presence of hiring and training costs. A related second motivation is that changing the size of the workforce can be disruptive in terms of the coordination and teamwork across workers. Both of these ideas better motivate internal rather than external adjustment costs. Of course, some hiring and training costs arguably do not directly affect productivity but rather reflect explicit costs. For example, some union agreements specify severance payments or other penalties for employment reductions. This distinction between internal and external adjust ment costs is of fundamental importance in this cent ext. While internal and external adjustment costs have similar implications with respect to employment dynamics, they have potentially very different implications with respect to productivity dynamics.

${ }^{4} T$ The focus of the intuitive discussion involves a productivity penalty for downsizing. As discussed in section 4 , a productivity penalty for upsizing would contribute to countercyclicality rather than procyclicality of labor.
} 
of this hypothesis is that the productivity impact of a demand or technology shock in a given plant should depend upon whether this decline is idiosyncratic to the plant or whether it occurs simultaneously in most manufacturing plants. Bart elsman et al. (1994) have found evidence for a modest posit ive relationship between downstream activity and productivity over the course of a business cycle. ${ }^{5}$

Lastly, we look at the effect of mix-shifts or industry composition on the measured procyclicality of aggregate labor productivity $y$ in manufacturing. Recent work investigating plant and firm level dynamics of productivity has shown the importance of distinguishing 'within' plant productivity growth and the effects of compositional change on the aggregate. Bartelsman and Dhrymes (1994) show that in a sample of large manufacturing plants, long-run total factor productivity (TFP) growth is mostly the results of compositional changes: on average, plant level productivity y does not increase over time, while, on balance, more productive plants become larger while less productive plants lose market share. A similar finding is reported in Baily, Hulten and Campbell (1992), who investigate all plants in a subset of 4-digit industries. By contrast, Baily, Bartelsman and Haltiwanger (1995) and Griliches and Regev (1992) find that for long-run labor productivity, most of the aggregate growth is the result of within plant growth.

While it is beyond the scope of this paper to reconcile these differing results on total factor productivity and labor productivity, the above mentioned research does suggest the possibility that the aggregate pattern of procyclical labor productivity may arise from a mix-shift effect. ${ }^{6}$ Perhaps, most plants display the neoclassical pattern of countercyclical productivity, but the aggregate data are 'distorted' by the mix changes. For this hypothesis to be correct, it would mean that below average productivity plaints have larger shares of employment in recessions than they have in booms, or that the net effect of entry and exit on productivity has a clear procyclical pattern.

3 Data Description and Exploration

\subsection{Data Description}

In this study we make use of a sample of manufacturing plants from the Longitudinal Research Database(LRD), available at the Bureau of the Census. our sample consists of those plants which were in continuous operation from 1972 through 1988, and had positive employment and shipments

\footnotetext{
${ }^{5}$ In many ways, the current paper can be interpreted as exploiting within sector, between plant differences ' $n$ 'he sectoral level results found in Bartelsman et al. (1994).

${ }^{6}$ Similar decompositions have been made for the cyclical variation in real wages - See the recent survey by Abraham and Halt iwanger (1995). The consensus that emerges from these st udies is that there is a counter cyclical composition bias in real wages induced by the fact that lower skilled workers tend to be laid off first in recessions. After correcting for this composition bias, researchers have typically found that wages are procyclical.

${ }^{7}$ In our investigation we use a balanced panel of plants and cannot check the net effect of entry and exit directly. We do not think that this effect is disproportionate, in any case, since the cyclical pattern of productivity in our sample is similar to that of the aggregate. In fact, the subsequent discussion of Chart 1 suggests that if anything net entry yields a countercyclical contribution to productivity over the cycle.
} 
in all years. Given the nature of the Annual Surveys of Manufactures, this selection criterion provides us with a sample of firms which are much larger than average. Table 1 provides summary stat istics of our sample, compared with all manufacturing for 1987. As shown, we cover less than 2-1/2 percent of plants, but nearly half of the output in manufacturing.

Chart 1 provides a comparison of our LRD sample with data for all manufacturing. The top panel shows output and employment for all manufacturing, the middle panel displays the same series for our LRD sample, while the bottom panel compares output per hour from our sample with that from all manufacturing. Output is measured as deflated shipments plus inventory changes, using 4-digit benchmark- years weighted out put deflators. ${ }^{8}$ Employment is measured in hours, and is constructed as the sum of production worker hours and non-production workers multiplied by the average length of their workweek. Annual time series on the workweek for non-production workers is computed for 2- and some 3-digit industry groupings using information from the Current Population Survey. In later analysis, we also look at variants of employment and productivity, with out put measured by double-deflated value added, and employment measured by total number of employees.

The central point of Chart 1 is that the basic aggregate properties of output, employment, and productivity fluctuations for our sample are the same as those exhibited by the published series. Specifically, for our sample and the published series, out put and tot al hours are procyclical, out put is more cyclically volatile than total hours and, accordingly, average labor productivity is procyclical. There are some quantitative differences in the nature of the cyclicality between our sample and the published series that we explore below.

\subsection{The Contribution of Simple Composition Effects}

We now turn to the last hypothesis for procyclical productivity, that of composition effects. As stat ed earlier, we are not able to discuss the effect of plant turnover on productivity movements directly. As seen in the bottom panel of chart 1, however, our sample appears to have more cyclical productivity than the aggregate for all manufacturing. This would agree with our prior belief that less productive plants are more likely to exit in a trough, and reduce the procyclicality of the aggregate.

For our sample of cent inuing plants, we can decompose annual productivity changes into a 'within' plant component, and two mix-shift terms: an employment share effect, and a cross term.

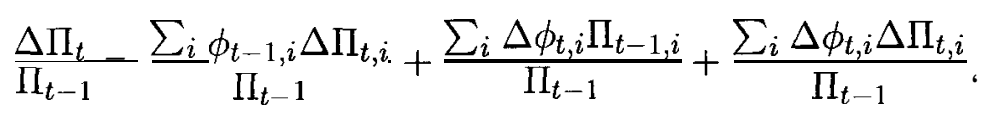

'The deflators and data for total manufacturing are computed from the 4-digit NBER Manufacturing Productivity Database, available via anonymous FTP from nber.harvard.edu. See Bartelsman and Gray (1995) for a description of these data. 
Table 1: 1987 Summary Statistics: All Mfg. vs. LRDSample

\begin{tabular}{lrrr}
\hline & All Mfg. & LRD & Sample Sample as \% of All \\
\hline Establishments & 368897 & 8669 & 2.34 \\
Output (Billions) & 2329.6 & 1100.7 & 47.25 \\
Employment (000) & 17406.5 & 6332.8 & 36.38 \\
Avg. Estab. Size & 47 & 731 & \\
& & & \\
Plant Distribution & & & \\
By SIC & & & \\
20 & 20583 & 891 & 4.33 \\
21 & 137 & 22 & 16.06 \\
22 & 6065 & 608 & 10.02 \\
23 & 23168 & 519 & 2.24 \\
24 & 33987 & 180 & 0.53 \\
25 & 11636 & 247 & 2.12 \\
26 & 6292 & 430 & 6.83 \\
27 & 61791 & 431 & 6.98 \\
28 & 12039 & 537 & 4.46 \\
29 & 2232 & 103 & 4.61 \\
30 & 14589 & 332 & 2.28 \\
31 & 2198 & 143 & 6.51 \\
32 & 16191 & 299 & 1.85 \\
33 & 6661 & 506 & 7.60 \\
34 & 36092 & 721 & 2.00 \\
35 & 52091 & 859 & 1.65 \\
36 & 15922 & 918 & 5.76 \\
37 & 10505 & 505 & 4.81 \\
38 & 10193 & 276 & 2.71 \\
39 & 16573 & 142 & 0.86 \\
\hline
\end{tabular}

* Excludes computers, SIC 3573. 
where $\Pi_{i}$ is output per hour in plant $i, L_{i}$ shows employee hours in plant $i$, and $\phi_{i}=\frac{L_{i}}{\sum_{j} L_{j}}$.

Chart 2 shows the time series behavior of the three components over our sample period. The productivity (within plant) term exhibits pronounced procyclical behavior, with sharp increases in the recovery years 1976 and 1983. The first mix term (employment share) rises because of shifts in employment shares between plants, This term is positive or negat ive depending upon whether the plants that are above average in productivity are increasing or decreasing their shares of employment. There was a substantial employment effect that increased productivity in 1981, 82, and 83. Cyclical episodes thus tend to shake the plants up in the "right" direction, that is, it raised the employment share of above average plants.

The cross-term was negative in the early 1980s, indicating that plants that increased productivity more rapidly than average had declining employment shares - consistent with the fact that some plants were more successful than others in adjusting their employment over the period. On balance, however, this term is quite small.

\subsection{Basic Facts: Long-run Structural Change and Cyclical Dynamics}

Although there are non-trivial mix effects shown in these data, it seems that a fair general characterization of the results is that procyclical productivity is a within-plant phenomenon. Even though the cyclical variation in productivity is primarily due to within-plant effects, this does not imply that there are no cross sectional differences across plants that are in important in accounting for the procyclicality of productivity. For example, Baily, Bartelsman and Haltiwanger (1995) have shown that there are import ant cross sect ional differences across plants that are important in accounting for the secular growth in productivity in the U.S. manufacturing sector in the 1980s. Surprisingly, plants that upsized (increased employment) and increased productivity accounted for about as much of the increase in overall productivity as plants that downsized and increased productivity. Over the 1980s, upsizing plants that increased productivity saw their share of manufacturing output increase from about $20 \%$ to $40 \%$ which is one of the primary reasons that aggregate productivity increased over this period.

The long-run differences between upsizing plants and downsizing plants potentially have important implications for short-run cyclical changes as well. As discussed in section 2, cyclical productivity fluctuations are naturally linked to long-run structural changes. The evidence of subst ant ial heterogeneity $y$ in the long-run structural changes found by Baily, Bart elsman and Halt iwanger (1995) thus provides a source of variation in the data that can be exploited to identify the relative cent ribution of alternative explanations of pro cyclical productivity $y$.

To begin this exploration of the connection between the cyclical variations in productivity and the long-run structural changes, we consider the cyclical productivity fluctuations of plants for each of four quadrants: plants where employment and productivity increased in the long run, plants where productivity increased and employment declined, plants where employment and pro- 
Figure 3: Employment and Productivity y Changes, 1979-88

\begin{tabular}{cc|cc} 
QUADRANT & 2 & Q U ADRANT & 1 \\
$\Delta$ Productivity & $>0$ & A Productivity & $>0$ \\
A Employment & $<0$ & A Employment & $>0$ \\
& & & \\
\hline & & & \\
Q U A A RANT & 3 & Q U ADRANT & 4 \\
A Productivity & $<0$ & A Productivity & $<0$ \\
A Employment & $<0$ & A Employment & $>0$
\end{tabular}

ductivity declined and plants where employment increased and productivity declined. Chart 3 gives a schematic of these quadrants.9

In section 2, we suggested that the relative importance of different explanations of procyclical productivity can be expected to vary systematically across plants depending on their long-run structural changes. As a way to explore this, Chart 4 shows the time series pattern of aggregate labor productivity $\mathrm{y}$ for each quadrant for our sample of plants, as well as average (or 'within' plant ) labor productivity y. Essentially, the series plotted are analytical decompositions of aggregat e employment and output which differ from those generally made available by statistical agencies. Instead of building aggregates by industry or region, the series are constructed by stratifying plants according to their long-run changes of employment and productivity.

Chart 4 shows that most of the cyclical variation is of the 'within' plant variety. Further, we see that quadrants 1 and 4 have less cyclical variation in productivity y than do quadrants 2 and 3: the variance of labor productivity of the plants in these quadrants is substantially lower than for the downsizing plants. These different patterns are suggestive that differences in long-run structural changes may be important in understanding cyclical variations in productivity. To understand the precise connection, we must impose some further structure on the analysis both theoretically and empirically. In the succeeding section, we sketch out some simple models to illustrate the potential connection between long-run structural changes and cyclical variations in productivity. The subsequent section empirically exploits the insights of the theory.

These are the same quadrant definitions used in Baily, Bartelsman and Haltiwanger (1995) but in that paper we used the universe of plants contained in the Census of Manufactures in 1977 and 1987 to conduct our analysis. This enabled us to quantify the role of entry and exit as well as continuing plants in accounting for productivity growth over the 1980s. 
Our analysis builds off specific cases of the following general production function:

$$
Y_{i t}=A_{i t} F\left(u_{i t} K_{i t}, e_{i t} L_{i t}, M_{i t}, N_{i t}, R_{i t}\right) Y_{t}^{\epsilon}
$$

where $Y_{i t}$ is output at establishment i at time t, $A_{i t}$ reflects the level of technology at establishment i at time t, $K_{i t}$ is the capital stock, $u_{i t}$ is the capital utilization rate, Lit is total hours of labor, $e_{i t}$ is the effort per unit of labor (typically unmeasured), $M_{i t}$ is a measure of human capital or perhaps maintenance capital (explained below), $N_{i t}$ is new hires, $R_{i t}$ is layoffs, and $Y_{t}$ is economywide out put .

Our methodology for isolating the different sources of procyclical productivity present in equation (2) is based on examining the cyclical behavior of plants facing similar cyclical shocks but facing different long--run growth rates in demand and technological progress. Each plant is assumed to face a constant elasticity demand curve each period with the inverse demand schedule given by $P_{i t}=D_{i t} \eta_{t} Y_{i t}^{\mu}$ where $P_{i t}$ as the price for the output supplied by establishment i in period $\mathrm{t}, D_{i t}$ is an idiosyncratic demand shifter, $\eta_{t}$ is a common stochastic demand shock (assumed to be i.i.d.), and $\mu$ is a negative constant, To capture the evolution of idiosyncratic demand and technological conditions in a simple fashion, we assume that:

$$
\begin{aligned}
& D_{i t}=\left(1+g_{i}^{P}\right) D_{i t-1} \\
& A_{i t}=\left(1+g_{i}^{A}\right) A_{i t-1}
\end{aligned}
$$

where $g_{i}^{P}$ reflects establishment-specific growth in demand conditions and $g_{i}^{A}$ reflects establishmentspecific growth in technological progress.

Several remarks are in order. First, the results are generally robust to assuming that individual producers are price takers (i.e., $\mu=0$ ). Viewed from this latter perspective, it is more appropriate to interpret this specification as representing the evolution of demand for specific sectors (perhaps very narrowly defined) rather than for specific est abolishments.

A second remark is that we focus on demand disturbances as the ultimate source of cyclical fluctuations. We do this for two reasons. First, cyclical fluctuations driven by technology shocks generate procyclical labor productivity by construction. Our interest is in investigating explanations of procyclical labor productivity not driven by technology shocks. Second, in a related manner, our subsequent empirical analysis focuses on the component of cyclical labor productivity driven by demand shocks.

In the next sections we consider in turn each of the possible explanations of the procyclicality of productivity and examine how the implications interact with long-run structural changes. 


\subsection{Labor Hoarding}

The hypothesis of labor hoarding is intimately linked to the appropriate measurement oft he labor input and to the alternative productive uses of the labor input. The labor input can be thought of as composed of two components: time spent directly on production, denoted $x_{i t}$, and time spent on maintenance or training, denoted $m_{i t}$. In terms of the notation in (2), $e_{i t} L_{i t}=x_{i t}$ and $x_{i t}+m_{i t}=$ Lit. To capture the idea that time spent on maintenance or training is ultimately productive, we define $M_{i t}$ to be human capital or maintenance capital that accumulates as follows:

$$
M_{i t+1}=\left(1-\delta_{i}\right) M_{i t}+m_{i t}
$$

where $\delta_{i}$ is the depreciation rate for this form of capital.

For this specific case, the production function is assumed to be given by $Y_{i t}=A_{i t} F\left(x_{i t}, M_{i t}\right)$ where both inputs into the production function have positive marginal products. We omit the internal adjustment cost terms, externalities and physical capital (for this case) to focus on the implications of labor hoarding.

The value function characterizing the maximization problem faced by an individual establishment in this environment is given by: $:^{10}$

$$
V\left(M_{i t} ; D_{i t-1}, A_{i t-1}\right)=\max \left(P_{i t} A_{i t} F\left(x_{i t}, M_{i t}\right)-w_{t} L_{i t}+E\left[\beta V\left(M_{i t+1} ; D_{i t}, A_{i t}\right)\right]\right)
$$

where $\beta$ is the discount factor, $w_{t}$ is the common wage rate faced by all establishments, and the evolution of demand and technology conditions are given by equations (3) and (4).11

The maximization problem (6) yields a standard first order condition for employing labor and an Euler equation for accumulating maintenance/training capital given by:

$$
\begin{gathered}
\tilde{P}_{i t} A_{i t} F_{1 i t}=w_{t} \\
\tilde{P}_{i t} A_{i t} F_{1 i t}=\beta E\left[\tilde{P}_{i t+1} A_{i t+1}\left(\left(1-\delta_{i}\right) F_{1 i t+1}+F_{2 i t+1}\right)\right]
\end{gathered}
$$

where $\tilde{P}_{i t}=(1+\mu) \mathrm{ni}_{\mathrm{t}} \eta_{t} F_{i t}^{\mu}$ and $F_{1}$ it represents the derivative of the production function in time $t$ with respect to the first argument, and so on. Equation (7) is the standard condition that labor is employed directly in current production up to the point that the marginal revenue product of labor is equal to the wage. Equation (8) indicates that labor is utilized in maintenance/training activity to equate the marginal revenue product of labor in the current period with the expected discounted future value of an additional unit of maintenance capital.

For our purposes, the main result that emerges from equations (7) and (8) is that $m_{i t}$ is an

\footnotetext{
${ }^{10}$ We assume that the parameters of the production anddemand functions are such that this is a well-behaved concave maximization problem with a unique interior solution.

11 Implicit in the latter is the assumption that the plant faces a constant elasticity demand curve each period.
} 
increasing function of $g_{i}^{P}$ and $g_{i}^{12}$. This result is intuitive since it essentially states that the return to engaging in the maintenance/training activity is increasing in the growth rat es of demand and technological change. Since establishments with more favorable future conditions invest in more maintenance/t raining capital, this in turn implies that the magnitude of mismeasured labor effort is great er for establishments with higher long-run growth rates in demand and technological progress. Further, establishments with more favorable future conditions will exhibit higher long-run growth of employment - i.e., they will be the upsizers.

Formally, the cyclical responsiveness of average labor productivity is given by:

$$
\left(\partial x_{i t} / \partial \eta_{t}\right)\left[\left(\left(x_{i t}+m_{i t}\right) F_{1 i t}{ }^{-} F_{i t}\right) /\left(x_{i t}+m_{i t}\right)^{2}\right]
$$

Equation (9) indicates that incorporating the possibility of maintenance/training capital provides the potent ial for accounting for procyclical productivity through the mismeasurement of labor effort. Further, the magnitude of the mismeasurement of labor effort is greater for upsizing plants which in turn implies that if this is the driving force underlying procyclical productivity then this effect should be more important for up sizing plants. ${ }^{13}$ In terms of our quadrant definitions, this implies that est abolishments in quadrants 1 and 4 (the long-run upsizers) should be more likely to exhibit procyclical productivity. This is the key prediction of this model that we test in the empirical analysis.

\subsection{Product ivit y Penalty From Changing Scale of operations}

We now turn our attention to adjustment costs that involve a disruption in productivity when the scale of operations is altered. As discussed in section 2, there may be other aspects of adjustment costs that are import ant in employment $d$ ynamics that affect the volatility of employment and output but do not have direct implications for productivity.

For this specific case, we focus on a specification of the production function given by $Y_{i t}=$ $A_{i t} F\left(L_{i t}, N_{i t}, R_{i t}\right)$ where $L_{i t}=L_{i t-1}+N_{i t}-R_{i t}$. The key assumptions are that the derivatives of the production function with respect to the second and third arguments are both negative and the

\footnotetext{
12 The details of the results in this section are derived in Appendix A.

${ }^{13}$ We thank Dale Mortensen for pointing out to us that the model and implied results become substantially more complicated when $\eta_{t}$ exhibits serial correlation. In the latter case, the effect in equation (9) is still present but there is an additional effect involving the response of $m_{i t}$ to $\eta_{t}$. Since maintenance activity only yields returns in the future, under the i id assumption for the cyclical shock $m_{i t}$ is independent of the realization of $\eta_{t}$. However, with serial correlation, this independence no longer holds. A number of issuesare then potentially relevant. First, the nature of the serial dependence is relevant - simple first order positive serial correlation would imply procyclical maintenance capital while a simple Markov switching rule with demand switching between high and low states with probability one each period would yield countercyclical maintenance capital. In addition, for our purposes we need to know the sensitivity of the cyclicality of $m_{i t}$ to long run conditions. The latter will depend on third derivatives that we know relatively little about. We emphasize the simpler case with iid shocks because it highlights the interaction of the mismeasurement of labor with long run structural changes and it is the mismeasurement of labor which is at the center of the empirical literature on labor hoarding.
} 
marginal adjustment cost is increasing (i.e., $F_{22}<0$ and $\left.F_{33}<0\right) .{ }^{14}$

A key feature of this specification is $t$ hat the negative second and third derivatives have opposite effects on the cyclicality of productivity. The productivity penalty associated with hiring will tend to dampen any forces generating procyclical productivity. In contrast, the productivity penalty associated with making layoffs will tend to reinforce any forces generating procyclical productivity. A related important element of this specification is that the productivity disruption associated with changing the scale of operations can be asymmetric. ${ }^{15}$

For this model, the value function characterizing the maximization problem for establishment $\mathrm{i}$ at time $\mathrm{t}$ is given by:

$$
V\left(L_{i t-1} ; D_{i t-1}, A_{i t-1}\right)=\max \left(P_{i t} A_{i t} F\left(L_{i t}, N_{i t}, R_{i t}\right)-w_{t} L_{i t}+E\left[\beta V\left(L_{i t} ; D_{i t}, A i t\right)\right]\right)
$$

The evolution of demand and technology are assumed to be the same as in the previous subsection (i.e., given by equations (3) and (4)). The Euler equations are given by:

$$
\begin{aligned}
\tilde{P}_{i t} A_{i t}\left(F_{1 i t}+F_{2 i t}\right) & -\beta E\left[\tilde{P}_{i t+1} A_{i t+1} F_{2 i t+1} \mid N_{i t+1}>0\right] \\
& +\beta E\left[\tilde{P}_{i t+1} A_{i t+1} F_{3 i t+1} \mid R_{i t+1}>0\right]=w_{t} \text {, if } N_{i t}>0 \\
\tilde{P}_{i t} A_{i t}\left(F_{1 i t}-F_{3 i t}\right) \quad & -\beta E\left[\tilde{P}_{i t+1} A_{i t+1} F_{2 i t+1} \mid N_{i t+1}>0\right] \\
& +\beta E\left[\tilde{P}_{i t+1} A_{i t+1} F_{3 i t+1} \mid R_{i t+1}>0\right]=w_{t}, \text { if } R_{i t}>0
\end{aligned}
$$

where $\tilde{P}_{i t}=(1+\mu) D_{i t} \eta_{t} F_{i t}^{\mu}$.

A quick comparison of these two equations imply that new hires and layoffs will not occur simultaneously. An est abolishment making layoffs today takes into account both the current and the expected future adjustment costs in making employment adjustments. The latter in turn depend on future demand and $\mathrm{t}$ ethnology conditions. The impact of expected future adjustment costs implies that an establishment will reduce employment by a greater amount in response to an adverse current demand shock (represent ed by a lower $\tilde{P}_{i t}$ ) the lower is the expected future growth of demand and technology (represented by a lower $\tilde{P}_{i t+1}$ and $\left.A_{i t+1}\right) .{ }^{16}$ This result in turn implies that an establishment that anticipates it will be contracting in the future will exhibit a greater contraction of employment today in response to an adverse demand shock.

In this specification, average labor productivity is given by $F\left(L_{i t}, \mathrm{Nit}, R_{i t}\right) /\left(L_{i t-1}+N_{i t}-R_{i t}\right)$. When making layoffs (i.e., $\left.R_{i t}>0\right)$ the cyclical responsiveness of average labor productivity is given by:

\footnotetext{
${ }^{14}$ We assume that $F($.$) is continuously differentiable.$

${ }^{15}$ This asymmetry does not imply the type of non-differentiability of adjustment costs at zero that is emphasized by Bentolila and Bertola (1992). In fact, our derivation of results assumes continuous differentiability of $F($.$) .$

${ }_{16}$ The details of the derivation of the results in this section are presented in Appendix A.
} 


$$
\text { - }\left(\partial R_{i t} / \partial \eta_{t}\right)\left[\left(\left(F_{1 i t}-F_{3 i t}\right) L_{i t}-F_{i t}\right) /\left(L_{i t}^{2}\right)\right]
$$

Equation (13) implies that incorporating the possibility of a productivity penalty from downsizing provides the potential for accounting for procyclical productivity through a productivity penalty associated with downsizing. Since $F_{33}<0$, the greater layoffs by downsizing plants yields a greater productivity penalty for such plants and thus if this is the driving force underlying procyclical productivity then it should be the long-run downsizing plants that exhibit the greatest procyclicality. In terms oft he quadrant definitions, the hypothesis is that long-run downsizers (quadrants 2 and 3) make greater layoffs in response to a common adverse cyclical shock which in turn implies that they will suffer a greater productivity disruption from adjusting the scale of operations downwards.

\subsection{Increasing Ret urns - Internal vs. External}

Internal increasing returns is characterized by assuming that $\mathrm{F}($.$) exhibits increasing returns with$ respect to capital and labor. To illustrate the possible connection between short-run procyclical productivity and long-run increasing returns, we consider a production function given by $Y_{i t}=$ $A_{i t}\left(u_{i t} K_{i t}\right)^{\alpha} L_{i t}^{\beta}$ where $u_{i t}$ is the capital utilization rate and $\alpha+\beta>1$. Assume further that capital is fixed in the short run but that capital utilization is proportional to employment so that $u_{i t}=\phi L_{i t} .{ }^{17}$ With the same assumptions about the evolution of demand and technology conditions used in the previous sections (and the same not at ion for marginal revenue), this specification implies the following standard static first order condition for employment in the short run given by:

$$
\tilde{P}_{i t} A_{i t}(\alpha+\beta)\left(\phi K_{i t}\right)^{\alpha} L_{i t}^{\alpha+\beta-1}=w_{t}
$$

Equation (14) implies procyclical employment. Given that average labor productivity in this case is given by $A_{i t}\left(\phi K_{i t}\right)^{\alpha} L_{i t}^{\alpha+\beta-1}$ and $\alpha+\beta>1$, this result implies short-run procyclical labor productivity. Further, by construction long-run changes in output and inputs will also exhibit increasing returns, Putting these two results together yields the key idea for our purposes: plants with increasing returns should exhibit behavior consistent with increasing returns in both the short run and the long run. Establishments with increasing employment and increasing productivity over the long run (as well as est abolishments that exhibit decreasing employment and decreasing productivity) should exhibit behavior that is consistent with increasing returns. Accordingly, it should especially be these establishments (establishments in quadrants 1 and 3 in our classificat ion of the previous section) that should exhibit procyclical productivity if increasing returns is the primary source of procyclical productivity. ${ }^{18}$

\footnotetext{
${ }^{17}$ This assumption of proportionality is related to but quite distinct from that used by Burnside, Eichenbaum and Rebelo (1995). The latter paper exploits the assumption that capital utilization is proportional to electricity consumpt ion.

${ }^{18} \mathrm{~A}$ weakness of this argument is the driving forces underlying long-run structural changes may induce changes
} 
In contrast, if external increasing returns is the primary source of procyclical productivity then all establishments should exhibit pro cyclical productivity. ${ }^{19}$ In terms of the quadrant definitions, this prediction implies that there should not be significant differences in the procyclicality across quadrants.

\subsection{Putting the Pieces Together}

In this section, we have sketched out simple models to show that different sources of procyclical productivity have different implications for establishments with different long-run structural changes in employment and productivity. The predictions in terms of our quadrant definitions are summarized briefly as follows. If labor hoarding is the primary source of procyclical productivity, then quadrants 1 and 4 should exhibit greater procyclicality. If adjustment costs due to downsizing are the primary source of procyclical productivity, then quadrants 2 and 3 should exhibit greater procyclicality. If internal increasing returns is the primary source of procyclical productivity, then quadrants 1 and 3 should exhibit greater procyclicalit y. Finally, if external increasing returns is the primary source of procyclicality, then it should be observable to the same degree in all quadrants.

\section{Empirical I mplementation}

Chart 4 provided suggestive evidence that quadrants 2 and 3 exhibit the most procyclicality. However, the differences in cyclical variation of labor productivity by ex-post quadrants do not suffice for identifying causes of procyclicality. First, the predictions outlined in section 4 are based on anticipated structural changes. That is, the predictions are based on anticipated or forecasted quadrants, not necessarily ex-post quadrants. In a related manner, ex post long-run structural change may be influenced by the short-run cyclical changes so that allocation into the ex post quadrants may endogenously interact wit $h$ the short-run cyclical variations in productivity. We correct for these related problems by making plant level projections of long-run changes, based on plant specific information prior to 1979.

An additional problem is that sectors may face differences in the magnitude of the cyclical shocks. This is a problem in this context to the extent that the quadrants have a specific sectoral composition so that the magnitude of the cyclical episodes vary systematically by quadrant. We correct for this problem by relating the plant level cyclical variation to a downstream demand indicator specific to the 4-digit industry to which the plant is assigned. ${ }^{20}$ An additional advantage

in factor intensities. To the extent that this is important, this approach for identifying the contribution of internal increasing returns is problematic.

${ }^{19}$ More precisely, productivity at each individual establishment should be increasing in the relevant measure driving the external economies.

${ }^{20}$ The downstream indicator is an index of activity of other industries and service sectors which purchase output from the industry in question. See Bartelsman, Caballero, and Lyons (1994) for a complete description. 
of using the downstream indicator to capture cyclical fluctuations is that for many industries (see Shea (1993)) this isolates the component of procyclical productivity associated with demand fluctuations. As argued by Shea (1993), downstream demand is a better demand instrument when the materials share of the output from the upstream industry in the total costs of the downstream industry is relatively low.

The results of our investigation are presented in tables 2 and $3 .^{21}$ In table 2, we present indicators of procyclicality of labor productivity for each of the quadrants, based on productivity as measured by gross output per employee hour. The first row shows the parameter estimates $\gamma_{q}$ of equation 15, which represent the average variance of productivity for all plants in each quadrant. The productivity measure is the residual of a time series regression for each plant of the log of labor productivity on a time trend.

$$
\operatorname{Var}\left(\pi_{i t}-\hat{a}_{i}-\hat{b}_{i} t\right)_{i}=\sum_{q} \gamma_{q} I_{q i}+\varepsilon_{i}
$$

where $\hat{a}$ and $\hat{b}$ are parameter estimates from regressing the productivity on a time trend $t$, and the quadrant indicator $I_{q i}=1$ if plant $i$ is in quadrant $q$, zero otherwise.

For the results shown in row $1, \pi_{i t}$ is the log level of labor productivity in plant $i$ at time $t$, and $I_{q i}$ indicates the quadrants derived from ex-post realizations of employment and labor productivity. The definitions of the quadrants are given below in equation 16 .

$$
\begin{aligned}
& I_{1 i}=1 \text { if } \Delta L_{i}>=0 \text { and } \Delta \pi_{i}>=0,0 \text { otherwise } \\
& I_{2 i}=1 \text { if } \Delta L_{i} \varangle 0 \text { and } \Delta \pi_{i}>=0,0 \text { otherwise } \\
& I_{3 i}=1 \text { if } \quad \mathrm{A}_{i}<0 \text { and } \Delta \pi_{i}<0, \quad 0 \text { otherwise } \\
& I_{4 i}=1 \text { if } \mathrm{AL}_{\mathrm{i}}>=0 \text { and } \Delta \pi_{i}<0,0 \text { otherwise, }
\end{aligned}
$$

where $A L$ and $\Delta \pi$ are the coefficients of a regression of the log of employment or productivity on a time trend. This reduces somewhat the dependence of the quadrants on measurement error in the beginning and end years.

The next row shows the same parameter estimates, but here for quadrants based on plant level expect at ions of long-run employment and productivity growth. The indicator $I_{q i}$ will now depend on the projected value of $A L$ and $\Delta \pi$ instead of its actual value, as shown in equation 16 . The projections are computed by regressing the ex-post realizations of these growth coefficients for the pooled observations in each 2-digit industry on a set of variables which are observable by the plant before 1979. These variables are: plant size (average employment in 1977 and 1978), plant wage

\footnotetext{
${ }^{21}$ We have also produced versions of tables 2 and 3 (not reported) with output measured as double-deflated value added instead of gross output. The results for value added roughly correspond to those described in the text.
} 
Table 2: Indicators of Cyclicality by Quadrant: Hours

\begin{tabular}{|c|c|c|c|c|c|}
\hline \multirow[t]{4}{*}{ Equation } & Quadrant & 1 & 2 & 3 & 4 \\
\hline & & $\Delta \pi>=0$ & $\Delta \pi>=0$ & $\Delta \pi<0$ & $\Delta \pi<0$ \\
\hline & & $A L>=0$ & $A L<0$ & $A L<0$ & $A L>=0$ \\
\hline & & $\gamma_{1}$ & $-1 / 2$ & $\gamma_{3}$ & $\gamma_{4}$ \\
\hline \multirow[t]{2}{*}{15} & ex-post & .031 & .043 & .068 & .039 \\
\hline & & $(.003)$ & $(.002)$ & $(.004)$ & $(.005)$ \\
\hline \multirow[t]{2}{*}{15} & forecast & .039 & .042 & .079 & .036 \\
\hline & & $(.004)$ & $(.002)$ & (.008) & $(.009)$ \\
\hline \multirow[t]{2}{*}{17} & ex-post & .090 & .513 & .189 & -.043 \\
\hline & & $(.031)$ & $(.027)$ & (.048) & $(.063)$ \\
\hline \multirow[t]{2}{*}{17} & forecast & .054 & .359 & .518 & .176 \\
\hline & & $(.041)$ & $(.023)$ & $(.074)$ & $(.123)$ \\
\hline
\end{tabular}

(average compensation per employee in 1977 and 1978), lagged plant productivity (average labor productivity in 1977 and 1978), plant age, plant productivity and employment growth rates from 1972 through 1978, cumulative real investment from 1972 through 1978 relative to average plant size, and controls for 4-digit industry region, and ownership type. The $R^{2}$ of these projection equations range from .1 to .65 across industries, The standard errors presented in row 2 (and 4) have been corrected for the fact the regressors are projected values.

In the next two rows of the table we show the relationship between movements in productivity and a downstream indicator. In the third row, we use ex-post quadrants, and in the fourth row we use the projected quadrants to estimate the following equation:

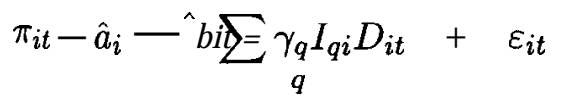

where $D_{i}$ is an index of downstream demand, defined for each 4-digit industry and applied to each plant based on its assigned 4-digit classification.

As seen in the table 2, plants in the downsizing quadrants, 2 and 3, have a larger variance of productivity and display a larger positive covariance between productivity and the downstream indicator, than do upsizing plants. This holds up for both the ex-post quadrants and the projected quadrants. The striking finding is that it is the plants that are permanently downsizing that account disproportionately for procyclical productivity. Plant that are experiencing long-run increases in employment (even based on the forecast able component of the long-run changes) exhibit little or no procyclicality once the variation in the magnitude of the cyclical episodes across quadrants has 
Table 3: Indicators of Cyclicality by Quadrant: Employment

\begin{tabular}{lrrrrr}
\hline Equation Quadrant & $\Delta \pi>=0$ & $\Delta \pi>=0$ & $\Delta \pi<0$ & $\Delta \pi<0$ \\
& & $\mathrm{AL}>=0$ & $\Delta L<0$ & $\Delta L<0$ & $\Delta L>=0$ \\
& & $\gamma_{1}$ & $\gamma_{2}$ & $\gamma_{3}$ & $\gamma_{4}$ \\
\hline 15 & ex-post & .030 & .044 & .068 & .039 \\
& & $(.004)$ & $(.003)$ & $(.005)$ & $(.006)$ \\
& & & & & \\
15 & forecast & .037 & .043 & .080 & .035 \\
& & $(.004)$ & $(.002)$ & $(.009)$ & $(.010)$ \\
& & & & & \\
17 & ex-post & .263 & .854 & .502 & .145 \\
& & $(.037)$ & $(.027)$ & $(.048)$ & $(.063)$ \\
17 & & & & & \\
& & .226 & .664 & .916 & .338 \\
& forecast & $(.041)$ & $(.023)$ & $(.074)$ & $(.123)$ \\
\hline
\end{tabular}

been taken into account.

We interpret these results to mean that the productivity penalty from downsizing plays a large role in accounting for pro cyclical productivity y of the aggregate, while labor hoarding plays a much smaller role, if any. Since all quadrants display at least some modest degree of procyclicalit y, we consider this as evidence that externalities related to downstream activity may play a modest role in aggregate procyclicality.22 Internal increasing returns to scale evidently is not a prime cause of procyclicality, otherwise we would have found the largest coefficients in quadrants 1 and 3 .

Table 3 display the same types of results as in table 2, but uses employment rather than hours to measure productivity. There are two reasons why the output per worker results are of interest. First, total hours at the plant level is more difficult to measure than total employment and thus it is useful to check whether results are robust across these measures. Second, a comparison of the results wit $\mathrm{h}$ those using output per hour yields further insights into the different margins of adjust ment that plants use in responding to shocks. ${ }^{23}$

The primary finding remains the same when using output per employee. That is, plants that are permanently downsizing (quadrants 2 and 3 ) disproportionately account for procyclical product ivity. However, all quadrants exhibit more procyclicalit y using employees rather than hours to measure labor productivity y. We see a much larger coefficient-around .25 larger -on downstream activity in quadrants 1 and 4 while the coefficients on downstream activity for quadrants 2 and 3

\footnotetext{
${ }^{22}$ Bartelsman, Caballero and Lyons (1994) found downstream externalities at the business cycle frequency of about 0.1 , even after correcting for capacity utilization. Here, quadrants 1 and 4 have coefficients between -.04 and .18, but these include both the effects of externalities and possible labor hoarding.

${ }^{23}$ See Mattey and Strongin ( 1994) for an interesting recent study of how margins of adjustment vary by type 'f manufacturing operation.
} 
are about .3 higher than in the output per hour table. This result reflects the well-known finding that hours per worker fall in recessions.

The fact that the difference between the cyclicality of output per worker and output per hour are about the same for all quadrants suggests that it is not labor hoarding which motivates plants to adjust hours per worker downwards in recessions. For if this were the case, then following the arguments discussed above, it should be in quadrants 1 and 4 that this effect should be especially important. Inst cad, this result indicates that all quadrants exhibit similar procyclicalit $y$ in hours per worker. Apparently, adjusting to an adverse cyclical shock in part by reducing hours per worker is common across plants with quite different long-run prospects. ${ }^{24}$

6

conclusions

In this paper, we exploit the cross sectional variation in long-run structural changes across plants to distinguish between different hypotheses for explaining the observed procyclicality of labor productivity. Using a large balanced panel of all continuously operating plants in the U.S. manufacturing sector during the 1970s and 1980s, we find that it is plants that are permanently downsizing that disproportionately account for procyclical productivity. Plants that are upsizing in the long run exhibit little or no procyclical productivity. These results favor an adjustment cost model which involves a productivity penalty for downsizing as the largest source of pro cyclical labor productivit $y$, although a modest role may be played by external economies. Internal increasing returns and labor hoarding appear to play little role, if any, in the procyclicality of productivity.

There are a number of directions that these striking findings could be explored further in future research. First, the role of capital adjustments in the dynamics of employment and labor productivity is an area of obvious interest. In addition, incorporating capital into the theoretical and empirical analysis would permit replication of our results for measures of total factor productivity. Second, our empirical approach has been descriptive and non-parametric rather than structural. In principle, it would be interesting to estimate a structural model that fully nests the competing hypotheses and that would allow a clean, precise decomposition of the factors accounting for procyclical productivity. However, we are a long way from being able to undertake this formidable task in this environment that stresses the interaction of plant-level heterogeneity $y$, long-run structural changes and cyclical variation.

\footnotetext{
${ }^{24}$ As suggested by the analysis of Bils (1987), Caballero and Engel (1993), and Caballero, Engel and Haltiwanger (1994), the costs of varying hours per worker and varying the number of workers is influenced by a number of factors. Consistent with the findings reported here, Caballero, Engel and Haltiwanger (1994) find that plants adjust to shocks first by changing hours per worker and only change the number of employees once the deviation between act ual and desired employment becomes sufficiently large.
} 
References

Abraham, Katherine and J ohn Haltiwanger, "Real Wages and the Business Cycle," J ournal of Economic Literature, 1995, 33.

Aizcorbe, Ana M., "Procyclical Labour Productivity, Increasing Returns to Labour, and Labour Hoarding in Car Assembly Plant Employment "“ Economic J ournal, July 1992, 102 (413), 860-73.

Baily, Martin N., Charles Hulten, and David Campbell, "The Distribution of Productivity in Manufacturing Plants, "in "Brookings Papers: Macroeconomics" Washington, D .C. 1992.

, Eric J. Bartelsman, and J ohn Haltiwanger, "Downsizing and Productivity Growth: Myth or Reality," in David G. Mayes, ed., Sources of Productivity Growth in the 1980s, Cambridge: Cambridge University Press, 1995.

Bartelsman, Eric J. and Phoebus J. Dhrymes, "Productivity Dynamics: US. Manufacturing Plants 1972- 1986," FEDS 94-1, Federal Reserve Board January 1994.

and Wayne Gray, "The NBER Manufacturing Productivity Database," J uly 1995. mimeo.

- Ricardo J. Caballero, and Richard K. Lyons, "Customer and Supplier Driven Externalies s," American Economic Review, September 1994, 34(84-4), 1075-84.

Bean, Charles R., "Endogenous Growth and the Procyclical Behavior of Productivity," European Economic Review, May 1990, 34 (2-3), 355-63.

Bentolila, Samuel and Giuseppe Bertola, "Firing Costs and Labor Demand: How Bad is Eurosclerosis?," Review of Economic Studies, 1992, 57, 381-402.

Bernanke, Ben and Martin Parkinson, "Procyclical Labor Productivity and Competing Theories of the Business Cycle: Some Evidence from Int erwar U.S. Manufacturing Industries," Journal of Political Economy, June 1991, 99 (3), 439-59.

Bils, Mark, "The Cyclical Behavior of Marginal Cost and Price," American Economic Review, December 1987, 77 (5), 838-55.

Brechling, Prank, Investment and Employment Decisions, Manchester: Manchester University Press, 1975.

Burnside, Craig, Martin Eichenbaum, and Sergio Rebelo, "Labor Hoarding and the Business Cycle," J ournal of Political Economy, April 1993, 101, 245-73.

$\ldots, \ldots$, and __ _ _Capital Utilization and Returns to Scale," February 1995. mimeo. 
Caballero, Ricardo and Eduardo Engel, "Macroeconomic Adjustment Hazards and Aggregate Dynamics," Quarterly Journal of Economics, May 1993, 108 (2), 313-58.

Caballero, Ricardo J., Eduardo M.R.A.Engel, and J ohn Haltiwanger, "Aggregate Employment Dynamics: Building from Macroeconomic Evidence," working paper 5042, NBER February 1994.

Davis, Steve and J ohn Haltiwanger, "Gross.Job Creation and Destruction: Macroeconomic Evidence and Macroeconomic Implications," in "NBER Macroeconomics Annual, V" 1990, pp. 123-68.

Fair, Ray C., The Short-run Demand for Workers and Hours, Amsterdam: North-Holland, 1969.

Fay, J . and J ames Medoff, "Labor and Output Over the Business Cycle," American Economic Review, 1985, 75, 638-55.

Gordon, Robert J ., "Are Procyclical Productivity Fluctuations a Figment of Measurement Error," 1990. Northwestern University.

Griliches, Zvi and Regev, Haim, "Productivity and Firm Turnover in Israeli Industry: 19791988," working paper 4059, National Bureau of Economic Research April 1992.

Hall, Robert E., "The Relation between Price and Marginal Cost in U.S. Industry," J ournal of Political Economy, October 1988, 96, 921-47.

_ , "E conometric Research on Shifts of production Functions at Medium and High Frequencies," August 1990. presented at Barcelona World Congress of the Econometric Society.

Hamermesh, Daniel and Gerald Pfann, "Adjustment Costs in Factor Demand," October 1994. mimeo.

Kuh, Edwin, "The Brookings Quarterly Econometric Model of the United States," in James Duesenberry, Gary Fromm, Lawrence Klein, and Edwin Kuh, eds., income Distribution and Employment Over the Business Cycle, Chicago: Rand McNally, 1965.

Mattey, J oe P. and Steve Strongin, "Factor Utilization and Margins for Adjusting Output: Evidence from Manufacturing Plants," November 1994. mimeo.

Oi, Walter Y., "Labor as a Quasi-Fixed Factor," J ournal of Political Economy, December 1962, 70, 538-55.

Saint-Paul, Gilles, "Productivity Growth and the Structure of the Business Cycle," European Economic Review, May 1993, 37 (4), 861-83. 
Sargent, Thomas, "Estimation of D ynamic Labor Demand Schedules Under Rational Expectations," J ournal of Political Economy, 1978, 86, 1009-1044.

Shea, J ohn, “DO Supply Curves Slope Up?," Quarterly J ournal of Economics, 1993, 108 (I), 1-32.

Solow, Robert M., "Some Evidence on the Short-Run Productivity Puzzle," in J. Baghwati and Eckaus R. S., eds., Development and Planning, London: Allen and Unwin, 1973, pp. 317-25. 


\subsection{Labor Hoarding}

The key result for this section is that $m_{i t}$ is increasing in $g_{i}^{P}$ and $g_{i}^{A}$. This result can be derived by rearranging equations (7) and (8) which yields $w_{t}=\left(\beta E\left[\tilde{P}_{i t+1} A_{i t+1}\left(F_{2 i t+1}\right)+\left(1-\delta_{i}\right) w_{t+1}\right]\right)$. In order to satisfy this relationship and equation(7) for period $\mathrm{t}+1$, an increase in expected future $\tilde{P}_{i t+1} A_{i t+1}$ must be met by an increase in $m_{i t}$.

This result implies that, other things equal, establishments with more favorable future demand and technology conditions are more likely to hoard labor in response to a current adverse demand shock. Consider two plants with identical initial and current conditions but one with higher expected growth in demand and technological progress. By identical initial conditions, we mean they both have the same prior period employment and maintenance capital. By the same current conditions we mean that hot $\mathrm{h}$ face the same adverse current demand shock. Thus, by (7), both plants will employ the same amount of labor directly in production. However, the plant with more favorable future conditions will have higher $m_{i t}$.

\subsection{Adjustment Costs}

The central result of this section is that an establishment will reduce employment by a greater amount in response to an adverse current demand shock (represented by a lower $P_{i t}$ ) the lower is the expected future growth of demand and technology (represented by a lower $\tilde{P}_{i t+1}$ and $A_{i t+1}$ ). This result is derived most easily in the extreme. Consider two plants that face identical initial and current conditions with both making layoffs this period due to a low current realization of demand. However, suppose one has sufficiently positive anticipated growth in demand that it will be hiring next period with certainty, but the other has sufficiently negative anticipated growth in demand that it will be laying off workers with certainty next period. Inspection of (12) across these two extremes immediately yields that the plant that is contracting in the future will make more layoffs in the current period. The same basic logic applies in the less extreme case. 
Chart 1: LRD Sample vs. All Manufacturing
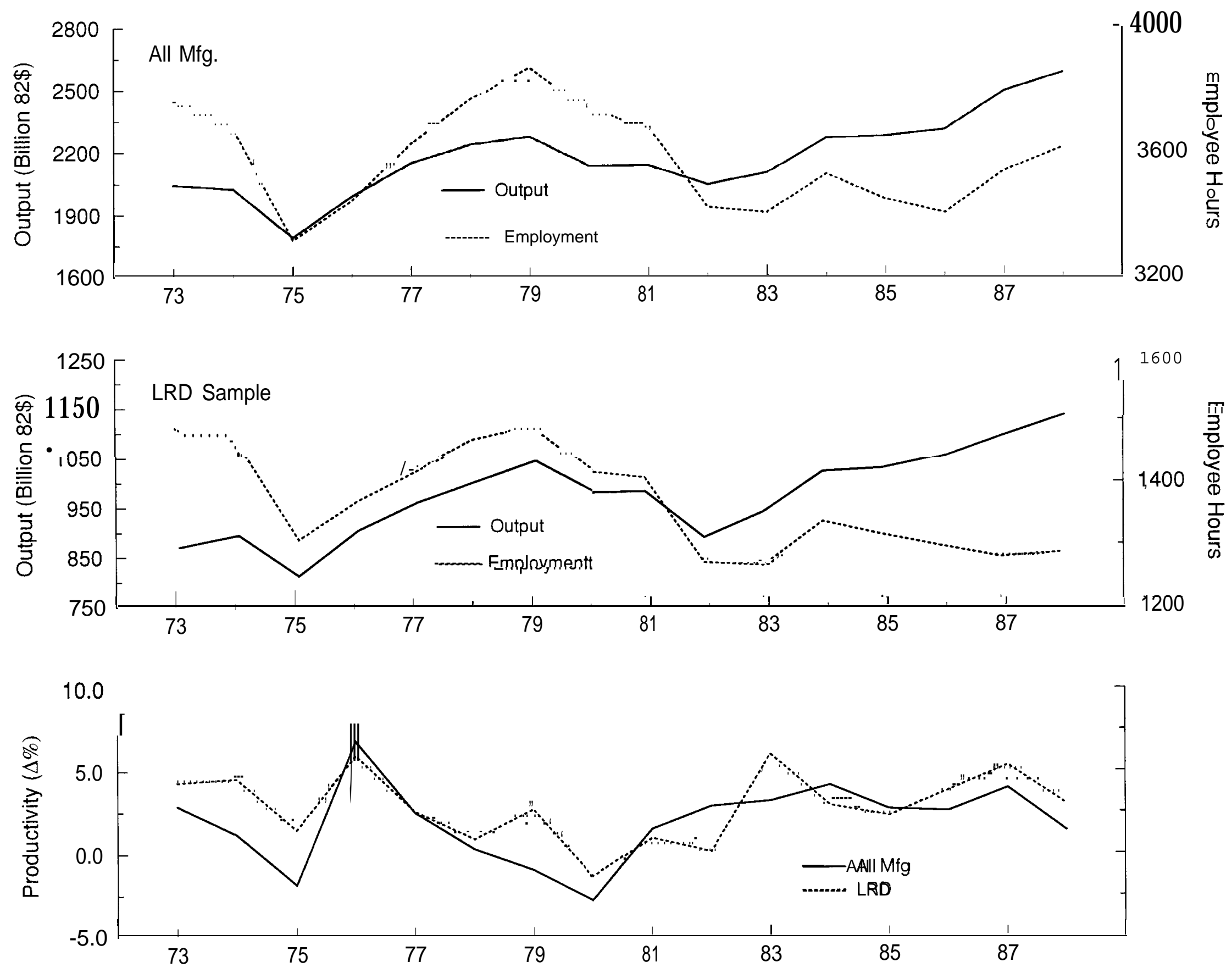


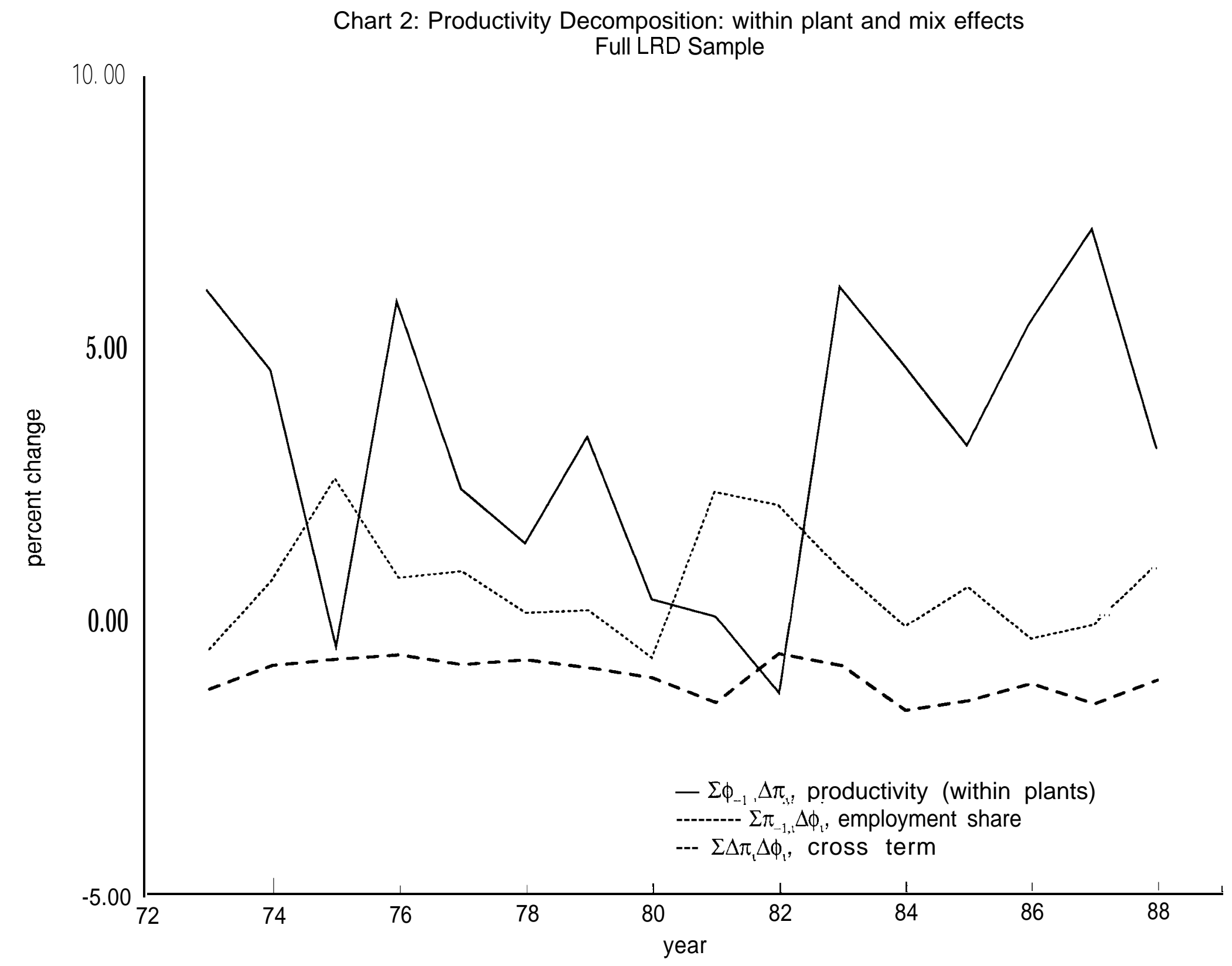




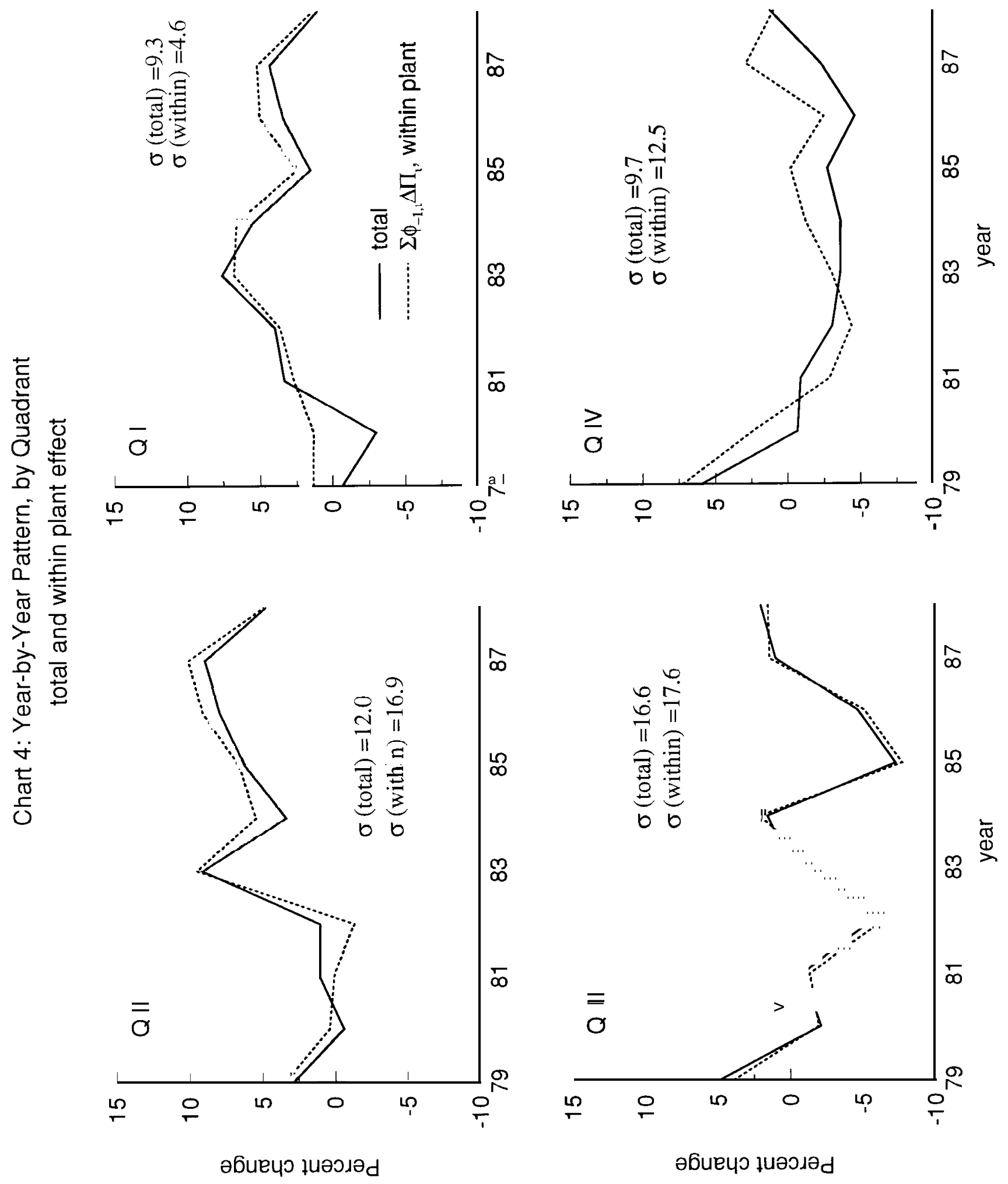

